\title{
MIR15B Pre-miRNA
}

National Cancer Institute

\section{Source}

National Cancer Institute. MIR15B Pre-miRNA. NCI Thesaurus. Code C82703.

MIR15B pre-miRNA is an oligoribonucleotide that is encoded by the human MIR15B gene and has a role in the regulation of gene expression. 